Hispania, LXIV/1, núm. 216 (2004)

\title{
ESTRATÉGIAS MATRIMONIAIS DA CASA \\ DE BRAGANÇA E O CASAMENTO \\ DO DUQUE D. JOÃO II
}

\author{
por \\ MAFALDA SOARES DA CUNHA \\ Universidade de Évora - CIDEHUS
}

RESUMEN: Este artículo se inicia con el análisis de las estrategias matrimoniales de la Casa de Bragança a largo plazo (1383-1640) con el fin de detectar y caracterizar sus lógicas evolutivas. A continuación se recorren algunos procesos negociadores relativos al concierto de matrimonio de algunos miembros de la Casa con el objetivo de explicitar el impacto de los cambios de coyuntura política sobre las lógicas de alianza promovidas por la Casa ducal de Bragança. En este contexto, el análisis de las negociaciones matrimoniales posteriores a 1580 revela tanto la pérdida de estatuto político junto a la realeza, como su posición periférica en la escena internacional.

Palabras Clave: Nobleza. Estrategias familiares. Portugal. Castilla. Casa de Bragança. Siglos XIV-XVII.

ABSTRACT: This article begins with an analysis of the long-term matrimonial strategies of the House of Braganza (1383-1640) with the end of determining and characterising the logic of their development. Next, it addresses some of the negotiating processes related to contracting marriage on the part of some members of the House, with the aim of making explicit the impact of changes in the political situation on the logic of alliances pursued by the ducal line of Braganza. In this context, the analysis of matrimonial alliances pursued after 1580 reveals both the loss of political status in comparison with the monarchy and the family's peripheral position on the international scene.

KEY WORDS: Nobility. Family. Portugal. Castile. House of Braganza. Early Modern period. Duke João II. 
Em 13 de Janeiro 1633, entrava em Vila Viçosa D. Luísa Francisca de Gusmão, filha do $8^{\circ}$ duque de Medina Sidónia, recém matrimoniada com D. João II, duque de Bragança. Sem o saberem, encerravam o ciclo dos casamentos ducais e abriam um período de quase cem anos sem que os Bragança buscassem uniões no reino vizinho.

A história dos casamentos ducais dos Bragança, longa de quase dois séculos e meio, é porventura um dos melhores e mais nítidos espelhos das suas estratégias políticas. A reconstituição dos itinerários das negociações matrimoniais revela como essas estratégias se alteraram com o passar dos tempos e a evolução das conjunturas, num constante diálogo entre os constrangimentos políticos externos e a prossecução dos interesses da casa.

Interesses associados ao acrescentamento ou à conservação do seu estatuto e espaço social o que significava sempre uma difícil e complexa definição de prioridades. Dessas prioridades dão conta as tentativas, as buscas, as dificuldades e os impedimentos que enxameiam o historial dos casamentos brigantinos. Talvez, por isso, os períodos das negociações matrimoniais sejam mais interessantes ainda do que as soluções encontradas, pois revelam de forma mais exacta o que, nos diferentes momentos, estava em jogo para a Casa de Bragança. Ou seja, o que desejava, o que considerava discutir, o que rejeitava, mas também o que lhe era permitido. As tomadas de decisão, que podem tanto significar opções deliberadas como a aceitação dos desfechos possíveis, revelam-nos, por último, o lugar da casa face à nobreza e face à Coroa.

\section{4-1483 OU A ESTRUTURAÇÃO DAS REDES NOBILIÁRQUICAS}

A estratégia de alianças familiares adoptada pelo Condestável Nuno Álvares Pereira permitiu-lhe acrescentar à dimensão territorial do senhorio que the fora doado, a proximidade de parentesco com a Casa Real portuguesa. É sabido que D. Beatriz, a sua única herdeira, casou em 1401 com D. Afonso, bastardo do rei D. João I, momento que Nuno Álvares aproveitou para conseguir que um dos seus títulos condais fosse confirmado no genro (condado de Barcelos). Mais tarde, alcançou idêntica mercê para os seus dois netos varões (condados de Ourém e de Arraiolos, 1422), distribuindo, assim, títulos nobiliárquicos entre os membros da sua casa, quando o dispositivo da titulação ainda não abrangera elementos exteriores à família real. A importância política granjeada foi ainda suficiente para reforçar as alianças familiares com a Casa Real através do casamento, em 1424, da única neta - D. Isabel - com o infante D. João, um dos. filhos mais novos do rey. D. João.I de Portugal.

A consolidação da posição social e política; através das uniões matrimoniais, prosseguiu nas gerações seguintes. Desta feita, conjugou-se o reforço das ligações à Casa Real com a penetração em reputadas linhagens medievais. Da elite fernandina (Noronha, Castro e os Meneses, condes de Vila Real), sobretudo, mas 
também com a integração de casas senhoriais trecentistas, que ascenderam ao patamar cimeiro da hierarquia nobiliárquica durante o século XV (os Melo, condes de Olivença $)^{1}$.

\section{QUADRO 1 \\ LINHAGENS PATERNA E MATERNA DOS CONJJUGES DOS MEMBROS DA CASA DE BRAGANÇA 1401-1483}

\begin{tabular}{|l|c|c|}
\hline LINHAGENS & PATERNA & MATERNA \\
\hline Família Real & 2 & 1 \\
\hline Noronha & 3 & \\
\hline Meneses & 2 & 2 \\
\hline Castro & 1 & 1 \\
\hline Bragança & & 1 \\
\hline Cunha & & 1 \\
\hline Sousa & 1 & 1 \\
\hline Melo & & 1 \\
\hline Miranda & & 1 \\
\hline Outra & & \\
\hline Total de casamentos & & \\
\hline
\end{tabular}

Excluindo os dois casamentos do primeiro duque, contabilizam-se nove uniões matrimoniais num total de onze descendentes. $\mathrm{O} 3^{\circ}$ duque foi o único que contraiu matrimónio duas vezes, ao passo que solteiros só ficaram um varão e duas senhoras ${ }^{2}$. Se se considerar que em dois destes casos houve uniões concertadas e que foi a morte que as impediu, o caracter excepcional do celibato fica claramente reforçado. Mas relativamente às qualidades sociais das uniões, importa ainda sublinhar que um dos vectores que também influenciou as escolhas de cônjuges foi o seu lugar na sucessão das respectivas casas senhoriais. Em cinco casos os Bragança consorciaram-se com sucessores de casas o que permitiu que o $3^{\circ}$ duque $\mathrm{D}$. Fernando fosse cunhado ou irmão de quatro dos mais ricos titulares do reinado de D. Afonso V (condes de Vila Real, Viana/Valença, Odemira/Faro e

1 Para uma análise mais detalhada dos percursos e importância relativa destas diferentes linhagens e do significado qué as diversas alianças matrimoniais tiveram na ascensão dos Bragança, ver CUNHA, Mafalda Soares da: Linhagem, Parentesco e Poder. A Casa de Bragança (1384-1483), Lisboa, Fundação da Casa de Bragança; 1990, pp. 19-70 (quadro in p. 47).

2 CUNHA, Mafalda Soares da: Linhagem, Parentesco e Poder, pp. 23-56. 
Olivença). Este facto também explica que a casa ducal recorresse sistematicamente ao matrimónio, quando, em muitas outras casas senhoriais, a adopção da primogenitura já empurrava os filhos mais novos para o celibato.

As uniões matrimoniais foram, pois, um instrumento decisivo na consolidação social da linhagem brigantina, permitindo a criação de redes de solidariedade e aliança com as principais casas nobiliárquicas. Utilizo o conceito de linhagem porque, embora a casa de Bragança tivesse já adoptado a primogenitura como sistema sucessório, as práticas sociais e familiares indiciavam um comportamento de tipo linhagístico. Tal facto revela-se, de resto, mais evidente no posicionamento político do grupo familiar. A própria percepção da época sobre o poderio brigantino dificilmente desligava as casas dos secundogénitos de uma estratégia política global encabeçada pelos duques de Bragança. Os comentários dos cronistas demonstram-no claramente, tanto por ocasião dos conflitos com o infante D. Pedro (que tiveram o seu epílogo na Batalha de Alfarrobeira, em 1449), quanto nos pedidos régios de aconselhamento sobre a política de expansão, no episódio da sucessão ao trono de Castela (Toro, 1476) ou, finalmente, nas ditas conspirações nobiliárquicas de 1483 . Em todos esses momentos e, também, nas investidas militares ao Norte de África, se fez sentir a presença dos Bragança, seja no comando de homens, seja na corte régia ou em sectores da administração central. A casa de Bragança era tomada e era, de facto, o pólo de uma rede social assente no parentesco e na defesa dos interesses senhoriais.

\section{6-1640 OU AS ESTRATÉGIAS DE DISTINÇÃO ${ }^{3}$}

Uma breve comparação entre as opções de casamento feitas no século XV e nos séculos XVI e XVII evidencia as alterações de comportamento nesta matéria. Como se viu, enquanto na centúria de quatrocentos se procurou quase sistematicamente casar todos os descendentes da casa, nos séculos XVI e XVII os investimentos matrimoniais reduziram-se significativamente. Dos vinte e quatro filhos que chegaram a idades núbeis, exceptuando os cinco sucessores, só oito casaram. Um total de dezasseis uniões, se incluirmos os recasamentos de dois dos duques. Os celibatários foram encaminhados para carreiras eclesiásticas (cinco) ou não tomaram qualquer estado (seis, dos quais cinco eram varões).

Esta alteração na intensidade de recurso ao matrimónio correspondeu igualmente à substituição de uma lógica linhagística por uma lógica de «casa» ${ }^{4}$. Ao alargamento dos recursos detidos pela linhagem (acumulação de juris-

3 Este ponto retoma algumas das considerações que se apresentaram muito abreviadamente in CUNHA, Mafalda Soares da: A Casa de Bragança. 1560-1640. Práticas senboriais e redes clientelares, Lisboa, Estampa, 2000, «introdução».

4 Sobre a definição dos conceitos de linhagem e «casa» ver, respectivamente, SoUSA, Bernardo Vasconcelos e: Os Pimentéis. Percursos de uma Linhagem Medieval Portuguesa (Séculos XIII-XIV), Lisboa, IN/CM, 2000, pp. 241 e ss. e bibliografia citada, e MONTEIRO, Nuno G.: «Poder Senhorial, 
dições pelo casamento de filhos com sucessoras de casas titulares com amplos senhorios, mas também diversificação de alianças entre a grande nobreza do Reino), sucedeu-se uma estratégia de distinção social que é comprovável pelo tipo de selecção de cônjuges para os primogénitos. Se excluirmos os dois casos das segundas núpcias dos $4^{\circ}$ e $5^{\circ}$ duques de Bragança, que parecem obedecer mais a inclinações pessoais que a qualquer estratégia reprodutiva, verificamos que, nos restantes cinco casamentos, a casa optou ou por alianças com Grandes de Castela, ou dentro da sua própria linhagem ou ainda na Casa Real. Este padrão de escolha reproduziu-se de modo bastante similar com os demais descendentes. Dos oito casamentos concertados, quatro incidiram em casas de titulares castelhanos, dois com a casa dos condes de Tentúgal/marqueses de Ferreira (do mesmo grupo linhagístico que os Bragança), um com a dos marqueses de Vila Real (com quem a casa tinha também tradição de alianças matrimoniais) e um com a família real (Quadro 2).

\section{QUADRO 2}

LINHAGENS PATERNA E MATERNA DOS CONNJUGES DOS MEMBROS DA CASA DE BRAGANÇA 1496-1640

\begin{tabular}{|l|c|c|}
\hline LINHAGENS & PATERNA & MATERNA \\
\hline Família Real & 2 & 1 \\
\hline Bragança & 1 & 1 \\
\hline Melo (Ferreira / Tentúgal) & 2 & \\
\hline Lencastre (Aveiro) & 1 & \\
\hline Meneses (Vila Real / Caminha) & 1 & \\
\hline Outras portuguesas & 1 & 4 \\
\hline Castelhanas & 8 & 10 \\
\hline Total de Casamentos & \multicolumn{2}{|c|}{16} \\
\hline
\end{tabular}

Quer isto dizer que se percebe existir uma estratégia clara de evitar alianças com a nobreza portuguesa. Quando tal ocorreu, seleccionaram-se as casas de melhor linhagem (Aveiro), e as que possibilitavam a renovação dos laços com a própria parentela (Ferreira/Tentúgal e Vila Real/Caminha). Casar fora, em Castela, era a estratégia da monarquia de Avis e também a que se afigurou mais conveniente para a casa de Bragança.

Estatuto Nobiliárquico e Aristocracia», História de Portugal, dir. José Mattoso, vol. IV, O Antigo Regime (1620-1807), coord. A. M. Hespanha, p. 365. 
Como se infere do Quadro 2, 56\% dos ascendentes, paternos e maternos, dos cônjuges dos Bragança eram castelhanos. A única diferença que nesta matéria se regista entre os períodos anterior e posterior a 1580 é o reforço da tendência para fazer casamentos em Castela, uma vez que depois de 1580, todas as uniões matrimoniais brigantinas foram concertadas entre a principal aristocracia desse reino.

\section{QUADRO 3}

LINHAGENS CASTELHANAS DOS CÔNJUGES CASTELHANOS DOS MEMBROS DA CASA DE BRAGANÇA, 1496-1640

\begin{tabular}{|c|c|c|c|}
\hline LINHAGENS CASTELHANAS & $\begin{array}{l}\text { MEMBRO DA CASA } \\
\text { DE BRAGANÇA }\end{array}$ & PATERNA & MATERNA \\
\hline Gusmão ( $3^{\circ} \mathrm{dq}$ Medina-Sidónia) & D. Jaime, $4^{\circ}$ duque & 1 & \\
\hline Velasco $\left(\mathrm{f}^{\mathrm{a}} 2^{\circ} \mathrm{c}\right.$ Haro $)$ & D. Jaime & & 1 \\
\hline Castro ( $2^{\circ}$ c Lemos) & D. Dinis & 1 & \\
\hline Osório ( $\mathrm{f}^{\mathrm{a}} 1^{\circ} \mathrm{mq}$ Astorga) & D. Dinis & & 1 \\
\hline Castro (c. Lemos) & D. Teodósio I, $5^{\circ}$ duque & & 1 \\
\hline Granada (neta do último rei Granada) & D. Teodósio $\mathrm{I}, 5^{\circ}$ duque & & 1 \\
\hline Cardenas ( $2^{\circ} \mathrm{dq}$ Maqueda e mq. Elche) & D. Joana & 1 & \\
\hline Velasco ( $2^{\circ}$ duque Frias) & D. Joana & & 1 \\
\hline Velasco ( $3^{\circ}$ duque Frias) & D. Teodósio II, $7^{\circ}$ duque & 1 & \\
\hline Girón ( $\mathrm{f}^{\mathrm{a}} 1^{\mathrm{o}}$ duque Ossuna) & D. Teodósio II, $7^{\circ}$ duque & & 1 \\
\hline Alvarez Toledo ( $5^{\circ}$ c Oropesa) & D. Duarte & 1 & \\
\hline Pimentel ( $f^{a} 6^{\circ} c$ Benavente) & D. Duarte & & 1 \\
\hline Pardo e Saavedra (sr. Malagón) & D. Duarte & 1 & \\
\hline Lacerda ( $\mathrm{f}^{\mathrm{a}} 1^{\circ} \mathrm{dq}$ Medinaceli) & D. Duarte & & 1 \\
\hline Pacheco (mq Vilhena, $5^{\circ} \mathrm{dq}$ Escalona) & D. Serafina & 1 & \\
\hline Alvarez de Toledo ( $4^{\circ}$ c Oropesa) & D. Serafina & & 1 \\
\hline Gusmão ( $8^{\circ} \mathrm{dq}$ Medina-Sidónia) & D. João II, $8^{\circ}$ duque & 1 & \\
\hline Sandoval (f $1^{\circ} \mathrm{dq}$ Lerma) & D. João II, $8^{\circ}$ duque & & 1 \\
\hline TOTAL & & 8 & 10 \\
\hline
\end{tabular}

O Quadro 3 comprova que os ascendentes castelhanos do cônjuges brigantinos eram todos da primeiríssima nobreza de Castela. Todos eram titulares e a quase totalidade usufruía do estatuto de Grandeza ${ }^{6}$.

5 Diferenciaram-se os casamentos anteriores e posteriores a 1580 pela utilização do negrito.

6 Uma lista de rendimentos das casas titulares de Espanha de 1577 fornece indicação daquelas que detinham essa distinção, Cf. British Library, Additional, ms. 40 026, fls. 247v-249.

Hispania, LXIV/1, núm. 216 (2004) 39-62 
QUADRO 4

RENDIMENTOS DAS CASAS TITULARES DOS CÔNJUGES CASTELHANOS DOS BRAGANÇA MILHARES DE DUCADOS / CONTOS DE RÉIS?

\begin{tabular}{|l|c|c|}
\hline $\begin{array}{c}\text { CASAS TITULARES DOS CôNJU- } \\
\text { GES CASTELHANOS }\end{array}$ & $\begin{array}{c}\text { MÉDIA RENDIMENTOS } \\
(1520-1597)\end{array}$ & $\begin{array}{c}\text { MÉDIA RENDIMENTOS } \\
(1610-1630)\end{array}$ \\
\hline Medina Sidónia, duques de & $125,3 / 50,120$ & $191,6 / 76,640$ \\
\hline Lerma, duques de & & $137 / 54,800$ \\
\hline Ossuna, duques de & $115,5 / 46,220$ & \\
\hline Escalona, duques de & $86,4 / 34,560$ & \\
\hline Benavente, condes de & $67,5 / 27,000$ & \\
\hline Frias, duques e Haro, condes de & $61,4 / 24,560$ & \\
\hline Maqueda, duques de & $48 / 19,200$ & \\
\hline Medinacelli, duques de & $38,6 / 15,440$ & \\
\hline Astorga, marqueses de & $37 / 14,800$ & \\
\hline Malagón, marqueses de & & $28,4 / 11,360$ \\
\hline Oropesa, condes de & $26,4 / 10,560$ & \\
\hline Lemos, condes de & $22,3 / 8,920$ & \\
\hline
\end{tabular}

Importa, todavia, observar que o nível dos rendimentos destas casas titulares de Espanha, com a excepção das de Medina Sidónia e de Lerma, era inferior ao da casa de Bragança que, em 1615, estava estimado em 48 contos de réis, ou seja 120,000 ducados (Quadro 4). Se se considerarem apenas as casas paternas - que para o efeito das negociações matrimoniais era sem dúvida a mais relevante - o destaque cabe apenas à de Medina Sidónia; que era, de resto, a mais rica da Península Ibérica. De qualquer mödo, o valor destes rendimentos médios se as situava bastante abaixo da casa de Bragança, colocava-as muito acima da maior parte das rendas das casas titulares portuguesas. Note-se que na já referida data de 1615 só os duques de Aveiro, os marqueses de Vila Real e os de Castelo Rodrigo tinham rendimentos superiores aos da casa dos condes de Lemos (respectivamente com 20, 13,2 e 12 contos de reis) que surge nesta lista como a de menores rendimentos.

7 Os valores apresentados só se reportam ao título principal e não incluem por isso os rendimentos decorrentes das eventuais uniões com outras casas que ocorreram ao longo do período em análise. Os dados utilizados para a construção das médias de rendimentos foram extraídos de AtienZa Hernändez, Ignacio, e SimÖn LöPeZ, Mina: Patronazgo Real, Rentas, Patrimonio Y Nobleza en los Siglos XVI y.XVII: Algunas notas para un analisis politico y socioeconomico, sep. Revista Internacional de Sociologia, Madrid, 2a época, vol. 45, fasc. 1, Jan-Março 1987.

Hispania, LXIV/1, núm. 216 (2004) 39-62 
Se estes indicadores contribuem para compreender a motivação na procura de noivas castelhanas, logo de dotes vultuosos, explicam menos bem a dos noivos. Esta limitação é, no entanto, imediatamente ultrapassada pela constatação de que, no conjunto, os Bragança privilegiaram de forma evidente o casamento de varões e não de fêmeas. Para estas valia o princípio muito eloquentemente expresso no contrato de dote de D. Catarina com o futuro duque D. João de que «filha de paes de tam grande sangue, e estado casara tão grandemente que

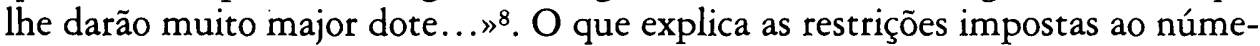
ro de matrimónios das descendentes femininas e que, de entre estas, só duas D. Joana, filha do $4^{\circ}$ duque, e D. Serafina, filha do $6^{\circ}$ duque - casassem em Espanha, respectivamente com o $2^{\circ}$ duque de Maqueda e marquês de Elche e $\operatorname{com} 5^{\circ}$ duque de Escalona e marquês de Vilhena.

A análise dos montantes dos dotes acordados (Quadro 5) cruzado com o estatuto das noivas castelhanas reforça esta interpretação. As cônjuges dos duques de Bragança trouxeram dotes significativos (a primeira 26 contos e as duas restantes 40 contos de reis) e as dos secundogénitos Bragança, para além do valor do dote, que também era considerável, ainda eram sucessoras das casas paternas. E esta posição de herdeiras únicas era seguramente mais relevante que o dote, uma vez que garantia ao noivo um estatuto social e económico assaz vantajoso e impossível de obter em Portugal.

Casar em Castela era, pois, uma solução conveniente para a casa de Bragança de vários pontos de vista. Evitavam-se excessos de proximidade e de familiaridade com a nobreza do reino e conseguiam-se uniões socialmente aceitáveis, o que dificilmente ocorreria no mercado matrimonial dos titulares portugueses. Como dizia o duque $\mathrm{D}$. Jaime «bem visto tinha quão poucos casamentos neste reino havia para elles [seus filhos]»?

De facto, esta dificuldade em casar os descendentes reflecte-se de forma razoavelmente óbvia nas idades de casamento dos membros da casa. Exceptuando a $1^{a}$ geração (a geração do $4^{\circ}$ duque), os restantes casaram muito tardiamente. Depois dos 25 anos, quando a idade média de casamento entre a nobreza, e em particular entre os sucessores das casas, era quase sempre pubertária (abaixo dos 20 anos). Mas também as diversas tentativas e a demora que se verificou aquando de cada uma das negociações de casamentos apoiam esta ideia.

8 SousA, António Caetano de: Provas da História Genealogica da Casa Real Portuguesa (PHGCRP), t. IV, P. 1ª Coimbra, Atlândida - Livraria Editora, 1950, p. 338. Daqui em diante será citado como Provas.

9 Carta ducal de 1630, transcrita na íntegra em PALHA, Fernando: $O$ Casamento do Infante $D$. Duarte com D. Isabel, Lisboa, Imprensa Nacional, 1881, p. 35.

Hispania, LXIV/1, núm. 216 (2004) 39-62 
QUADRO 5

DOTES DAS NOIVAS

\begin{tabular}{|c|c|c|c|}
\hline NoIVA & Norvo & DATA & MONTANTE EM CONTOS DE REIS 10 \\
\hline Leonor Mendonça & D. Jaime, $4^{\circ}$ duque & 1500 & 26 contos + legítima do pai \\
\hline D. Beatriz de Castro & D. Dinis & 1501 & $\begin{array}{c}\text { Herdeira. Vilas de Sarria, Castro e Outei- } \\
\text { ro d'El Rei }\end{array}$ \\
\hline Joana de Mendonça & D. Jaime, $4^{\circ}$ duque & 1520 & $\begin{array}{c}\text { Sem dote. «polo contentamento que tinha } \\
\text { della» }\end{array}$ \\
\hline D. Isabel & Inf. D. Duarte & 1536 & Ducado e vila de Guimaräes, etc. \\
\hline Isabel de Lencastre & D. Teodósio I, $5^{\circ}$ duque & 1542 & $\begin{array}{c}16 \text { contos + vilas várias. Tudo dado por } \\
\text { D. João III }\end{array}$ \\
\hline D. Eugénia & $\begin{array}{l}\text { D. Francisco de Melo - } \\
2^{\circ} \text { conde de Tentúgal }\end{array}$ & 1549 & 4 contos. Inclui legítima paterna. \\
\hline D. Joana & $\begin{array}{c}\text { D. Bernardino de Car- } \\
\text { denas - Marquês de } \\
\text { Elche }\end{array}$ & 1550 & 26 contos \\
\hline $\begin{array}{l}\text { D. Beatriz de } \\
\text { Lencastre }\end{array}$ & D. Teodósio $I, 5^{\circ}$ duque & 1559 & 20 contos \\
\hline $\begin{array}{l}\text { D. Maria de Melo } \\
\text { (Meneses) }\end{array}$ & D. Constantino & 1562 & 12 contos \\
\hline D. Catarina & D. João I, $6^{\circ}$ duque & 1563 & $\begin{array}{c}\text { Legítima do pai e a futura legítima da mãe } \\
+300000 \text { reis de tença }+ \text { jóias. Perfaz } \\
18,6 \text { contos réis }\end{array}$ \\
\hline D. Serafina & \begin{tabular}{|c|}
$\begin{array}{c}\text { D. João Fernandes Pache- } \\
\text { co-Marquês de Vilhena } \\
\text { e duque de Escalona }\end{array}$ \\
\end{tabular} & 1594 & $\begin{array}{c}24 \text { contos pagos por Filipe I (de Portugal) } \\
+8 \text { contos em jóias pagos pela duquesa } \\
\text { D. Catarina }\end{array}$ \\
\hline $\begin{array}{l}\text { D. Beatriz de Tole- } \\
\text { do, Monroy e Ayala }\end{array}$ & D. Duarte & 1595 & $\begin{array}{c}\text { Herdeira. }+3000 \text { ducados de alimentos. } \\
\text { Se não herdasse: } 40 \text { contos }\end{array}$ \\
\hline Ana Velasco & $\begin{array}{l}\text { D. Teodósio II, } 7^{\circ} \mathrm{du}- \\
\text { que }\end{array}$ & 1603 & $\begin{array}{c}40 \text { contos }+300 \text { quintais especiarias } \\
\text { indianas }+ \text { Vila do Conde }+2 \text { vezes fora } \\
\text { Lei Mental os bens doados a D. Teodósio } \\
\text { I, por ocasião seu casamento. Tudo doado } \\
\text { por Filipe II }\end{array}$ \\
\hline D. Isabel & \begin{tabular}{|c|} 
D. Miguel Luís de Mene- \\
ses $-6^{\circ}$ Marquês de Vila \\
Real, futuro $1^{\circ}$ duque de \\
Caminha
\end{tabular} & 1604 & $\begin{array}{l}16 \text { contos obrigatórios + legítima duque } \\
\text { seu pai + futura legítima de sua mãe. } \\
\text { Tudo estimado em cerca } 80 \text { contos. }\end{array}$ \\
\hline $\begin{array}{c}\begin{array}{c}\text { D. Guiomar Pardo } \\
\text { e Tavera }\end{array} \\
\end{array}$ & D. Duarte & ? & Senhora de casa de Malagón \\
\hline Luísa de Gusmão & D. João II, $8^{\circ}$ duque & 1632 & 40 contos \\
\hline
\end{tabular}

10 Estes dados foram extraídos dos contratos de casamento contidos em Provas, t. IV, P. $1^{\mathrm{a}}$ e P. $2^{\mathrm{a}}$, passim. 
É evidente que o leque de interesses em jogo era amplo e complexo e que por isso os intervenientes eram exigentes na hora de negociar. Em todo o caso há que ponderar que em causa estavam não apenas os interesses das casas senhoriais envolvidas, mas também os da Coroa. É sabido que a Monarquia portuguesa sempre se arrogou o direito de corroborar as opções senhoriais nessa matéria e que muitas vezes condicionou activamente as decisões. Também com os Bragança exerceu essa prerrogativa, sugerindo as uniões mais convenientes aos interesses da Coroa. D. Jaime, a propósito do seu próprio casamento com a filha do duque de Medina Sidónia, afirmou-o taxativamente. A intervenção da coroa no casamento da futura infanta $D$. Isabel demonstrou-o de novo, o mesmo ocorrendo após 1580 , como se verá adiante.

Importa, todavia, não esquecer que este direito régio era acompanhado da outorga de apoio às casas senhoriais e que estas comparticipações eram muitas vezes objecto de árduas negociações. $\mathrm{Na}$ composição do dote das noivas a monarquia colaborava com as casas numa percentagem variável. Para os casos em análise, oscilou entre nenhuma comparticipação e $75 \%$ do valor global estabelecido $^{11}$. Dependia, claro está, do interesse que o casamento suscitava junto do rei e também das disponibilidades momentâneas dos pais da nubente. No geral estes avançavam verbas para posterior desconto nas respectivas legítimas. Nem sempre chegava, porém. No já citado dote de D. Joana, uma vez que o montante negociado era muito elevado, conjugaram-se esforços. A monarquia, devidamente instada, apoiou ${ }^{12}$, mas também o fez a duquesa $\mathrm{D}$. Beatriz de Mendonça, sua mãe, através da alocação de 2 contos de réis recebidos da Imperatriz para o casamento de uma sua filha ${ }^{13}$. Já no que respeita aos sucessores, o mo-

11 No caso do dote de D. Joana o montante da comparticipação da Coroa estimou-se em 4 contos de réis (15\%), Provas, t. IV, P. 1a , p. 157, no de D. Serafina, 24 contos de réis, Provas, t. IV, P. $1^{\text {a }}$, p. 510 e ss e no de D. Isabel com o marquês de Vila Real, nenhuma, Provas, t. IV, P. $1^{\text {a }}$, p. 318.

12 Embora esta carta de D. Teodósio I ao rei denuncie uma hipótese de casamento que se não veio a concretizar, espelha muitíssimo bem os problemas levantados pelos concertos de casamento das descendentes femininas da casa de Bragança. Por esse motivo a incluo na íntegra, actualizando a ortografia: «Senhor. A duquesa minha mãe manda requerer a Vossa Alteza ajuda para casar dona Joana minha irmã e não o fizemos mais cedo porque cuidámos que com quarenta mil cruzados que the dou com sua legítima e com algum pouco mais que ela lhe dá se pudera casar em Castela e porque agora se fala em casamento seu com o marquês de Cuellar filho do duque de Albuquerque e ele está nisto mais lato do que cuidávamos parece que não poderá haver efeito sem a ajuda de Vossa Alteza porque eu é impossível dar-lhe mais e o que the tentio prometido com grande dificuldade o poderei pagar e seria grande lástima por míngua de uma pouca ajuda de Vossa Alteza perder-se este negócio porque minha irmã é de vinte cinco anos e em toda Espanha não há coisa que lhe possa armar se não // esta Beijarei as mãos de Vossa Alteza quererlhe fazer esta mercê e ainda que Vossa Alteza tenha dívidas e necessidades não queremos a mercê que pedimos logo se não acabado este contrato por se dizer que neste tempo se pagaram as dívidas de Flandres e lembre-se Vossa Alteza que é Dona Joana filha de meu pai que tanto serviu e minha irmã que bem cuido que por esta via não perderá merecimento ante Vossa Alteza cuja vida e real estado nosso senhor guarde e acrescente de Vila Viç̧osa a 24 de Março de 1546. Beijo as reais mãos de Vossa Alteza. O duque», IAN/TT, Corpo Cronológico, mço. 77, doc. 103.

13 Provas, t. IV, P. $1^{\text {a }}$, p. 311.

Hispania, LXIV/1, núm. 216 (2004) 39-62 
narca podia chegar a pagar a quase totalidade do dote da futura duquesa, traduzindo-se este não apenas em montantes pecuniários, como também na renovação em mais vidas de bens da Coroa já doados e outorga de novas mercês ${ }^{14}$.

Este breve apontamento esboça tendências de actuação que, naturalmente, escondem os diversos interesses conjunturais que a negociação de cada uma destas uniões suscitava. Embora na economia deste discurso não se justifique um grande aprofundamento do nível de análise, é pertinente apresentar alguns exemplos ilustrativos do tipo de problemas e de interesses envolvidos nos acordos matrimoniais. Um primeiro retomará o acerto do casamento de D. Isabel, filha do duque D. Jaime, com o infante D. Duarte. Outro, as negociações matrimoniais imediatamente posteriores a 1580 , com particular destaque para o caso de D. Teodósio II. Por fim o conturbado processo relativo ao casamento do $8^{\circ}$ duque de Bragança, D. João II.

\section{DILEMAS DE INTERESSES. O CASAMENTO DE D. ISABEL COM O INFANTE D. DUARTE}

A hipótese de unir D. Isabel a um dos filhos mais novos de D. Manuel parece ter colhido o duque $\mathrm{D}$. Jaime de surpresa. A proposta terá nascido de $\mathrm{D}$. João III e o medianeiro foi o conde da Castanheira. Aparentemente a decisão final dependia do montante do dote que o duque poderia disponibilizar. A primeira proposta de D. Jaime terá desagradado ao monarca, mas a rejeição régia agravou o duque que sentiu que o processo de decisão não visava o acrescentamento da sua honra, mas o serviço directo da Coroa. A carta que, por isso, escreveu ao monarca, em 1530 , constitui um documento extraordinariamente expressivo, quer do que o duque entendia deverem ser as relações da Coroa com a sua Casa, quer do que se jogava nas alianças matrimoniais ${ }^{15}$.

Muito sinteticamente dir-se-ia que D: Jaime adoptara uma posição aproximada da do seu antepassado Nuno Álvares Pereira, a propósito do concerto de casamento da sua única filha $\mathrm{D}$. Beatriz. Este rejeitara a proposta de união com o herdeiro do trono que sabia conduzir à extinção da sua recém constituída Casa. D. Jaime não se prestava a sacrificar significativamente a sua em prol da renovação dos laços com a família real. Dizia-o, de resto, aberta e arrogantemente «e se vossa alteza bem olhou que eu respondi a $\mathrm{D}$. Antonio, quando me da vossa parte fallou, bem devêra de ver que eu não havia de dar a minha filha cousa que me houvesse de desfazer nem destruir, porque eu lhe disse logo, que eu queria ainda mór bem a mim que a meus filhos, após mim a minha casa mais que a elles, e por

14 D. Teodósio I recebeu de D. João III o dote de D. Isabel de Lencastre, em que se incluíam as vilas de Monforte, Melgaço, Castro Laboreiro, Piconha, Vila Franca e Nogueira, com castelos, direitos e jurisdições de juro e herdade, fora da Lei Mental, mais 16 contos de réis, Provas, t. IV, P. $1^{a}$, p. 182. D. Teodósio II beneficiou do conjunto de mercês enumeradas no quadro 5, Provas, t. IV, P. $2^{2}$, pp. 117 e ss.. Quanto a D. João II, veja-se a lista das dádivas no final deste texto.

15 PALHA, Fernando: $O$ Casamento do Infante D. Duarte com D. Isabel..., pp. 26-35. 
isso não bavia de fazer cousa que desfizesse em meu filho berdeiro e na casa que lhe bavia de ficar, e porque tinha esta tenção estava bem fora de desejar para minha filha marido a que eu bouvesse de beijar a mão, e que queria antes casa-la com um bomem qua m'a beijasse a mim para o ter em minha casa para me aproveitar e servir d'elle, $e$ faria conta de lhe buscar de comer como bei de buscar para estoutros filhos machos... ${ }^{16}$. $\mathrm{O}$ maior ressentimento advinha, parece, da comparação que o rei teria feito a propósito do montante do dote explicitado «Vossa alteza me rechaçou tudo, despresando-o tanto que me comparastes com João da Guarda, e com a filha de Ruy de Mello, e com a filha de D. Francisco de Almeida, viúva de outro marido» acrescentando que «os casamentos que agora são grandes são de villãos ou christãos novos que por remir sua villania ou judearia quando querem haver pessoas de differente estado que são tão baixos que se querem vender por dinheiro, estes taes os compram, ou é de pessoas que vem da India ricos de roubar vossa alteza, que assim como lhe custa pouco a ganhar, tem em pouca conta de o dar». Inventariava de seguida os dotes concedidos nos diversos casamentos de infantas no século XV para comprovar a justeza do que oferecera ao monarca. Aduzia depois os méritos e a estima internacional que a sua Casa detinha, através de uma lista de propostas de casamento que lhe haviam sido feitas a ele, D. Jaime, quando se negociara a sua primeira união - as realizadas pelo imperador Maximiliano e pelo soberano inglês -, justificando a decisão a que se chegara pelo interesse de D. Manuel em atrair o duque de Medina Sidónia para a sua órbita motivado pela questão de Gibraltar («e comtudo el-rei meu senhor (...) por haver logo em breve o dinheiro de meu casamento e o duque meu sogro por servidor, que n'ella lhe podia muito servir concluiu o meu casamento...»).

A negociação não ficou por aqui. Interrompeu-se com as delongas do soberano, reatando o duque outras hipóteses. Uma delas era com o conde de Benavente ${ }^{17}$, outra com o conde de Oranha. Mas o necessário assentimento régio para esses acordos não foi dado. Protelou-se, assim, a questão até depois da morte de D. Jaime. Com D. Teodósio I veio por fim, mas não imediatamente, o acordo. E este correspondia bem à medida das expectativas do rei e não da Casa: largava-se o ducado de Guimarães e uma série de outras rendas. O casamento ocorreu em 1536, em Vila Viçosa; a contrapartida imediata que a Casa dele retirou foram as soberbas festas, realizadas com a pompa e circunstância que se conhece ${ }^{18}$.

16 PALHA, Fernando: O Casamento do Infante D. Duarte com D. Isabel..., p. 27. O itálico é meu.

17 Carta ducal, datada de Évora, 1533, ao Condestável de Castela sobre o casamento de D. Isabel com o conde de Benavente, BNM, Ms. 638, n. ${ }^{\circ}$ 50, fl. 123.

18 BNL, cód. 1544, BNL, cód. 484 e SousA, António Caetano de: História Genealógica da Casa Real Portuguesa (daqui em diante HGCRP), Coimbra, Atlântida Livraria Editora, t.VI.

Hispania, LXIV/1, núm. 216 (2004) 39-62 
Negócios De 1580. Os CASAMENTOS DOS FILHOS DA DUQUeSA D. CATARINA

Em 1580, a proposta que encabeçava as contrapartidas pedidas pela duquesa D. Catarina para a renúncia dos direitos sucessórios do reino de Portugal era a de casar a sua filha mais velha $\mathrm{D}$. Maria com o Príncipe herdeiro de Castela ${ }^{19}$. Como dote não se oferecia se não o direito de $\mathrm{D}$. Catarina ao trono.

A negociação de arranjos matrimoniais como meio de resolução de disputas territoriais por reclamação de heranças entre casas reais ou entre casas nobres era uma fórmula corrente. Havia inúmeros exemplos dessas situações. Em todas elas, porém, estava subentendido que ambas as partes reconheciam alguma legitimidade nas pretensões à sucessão do outro candidato. Ora se se pode claramente depreender deste pedido dos duques a aceitação da existência de direitos sucessórios por parte de Filipe II de Espanha ao trono português, ele também continha um pedido implícito por parte da casa de Bragança para similar reconhecimento por parte do Rei Prudente.

O fundamento negocial da duquesa $\mathrm{D}$. Catarina era a resolução do impasse sobre a sucessão ao trono de Portugal por via de «concerto e transacção» que era uma das três modalidades que ela apontava como sendo uso seguir-se quando havia dúvidas sobre tais matérias (as outras duas eram a justiça - e à data do início das negociações essa ainda não havia sido determinada por quem de direito - e a via das armas - que Filipe II se prestava a utilizar, mas que a duquesa rejeitava). É claro que as posições dos dois pretendentes eram diversas, uma vez que a esta análise o monarca castelhano contrapunha não haver dúvidas sobre a legitimidade dos seus direitos o que o levava a entender não carecer da renúncia dos direitos sucessórios da duquesa para, legitimamente, tomar posse do Reino de Portugal. Nesta óptica, o que D. Catarina propunha como contrapartidas contratuais, Filipe II entendia serem mercês graciosas. Disse-o, de resto, em carta datada de 10 de Novembro de 1580 «se havran de contentar con mostrarles que aquello procede de mi liberalidad y no de ningun genero de obligacion". Ou seja, a negociação com a Casa de Bragança deveria assemelharse a outras já concretizadas com várias casas senhoriais portuguesas. Daí o cuidado posto pelos agentes brigantinos em clarificar a possibilidade (e as eventuais hipóteses de sucesso) que os duques tinham de fazer valer os seus direitos, uma vez que a justiça se não pronunciara claramente sobre a matéria ${ }^{20}$.

Era, no fundo, esta a transcendente questão que estava em causa nesta proposta de negociação matrimonial, como muito bem compreenderam os políticos da causa dos Áustrias. Esse terá sido o motivo pelo qual, desde 1579, se procura-

19 Retomava de resto um reconhecido desejo do Cardeal-rei D. Henrique, como já em Setembro de 1579, Cristóvão de Moura transmitira ao rei, in VelLOSO, J.M. Queirós: O Interregno dos Governadores e o Breve Reinado de D. António, Lisboa, Academia Portuguesa de História, 1953, pp. 211-212

20 Cf. a já citada correspondência publicada por Velloso, J. M. Queirós em $O$ Interregno dos Governadores..., "Apêndice Documental», pp. 207 e ss.. A citação, supra, da carta de 10 de Novembro reporta-se à p. 271.

Hispania, LXIV/1, núm. 216 (2004) 39-62 
vam escusar a tal negócio, explicando que essa solução traria grandes vantagens à Casa de Bragança, mas muitos inconvenientes à monarquia, uma vez que faria o duque de Barcelos cunhado do rei de Espanha e este genro do duque de Bragança. Tal situação desgostaria não só os castelhanos, como também a própria nobreza portuguesa uma vez que «a grandeza e vanidad de la casa de Bergança les es odiosissima y creçiendola por este camino se les haria intolerable» ${ }^{21}$.

Embora de quase impossível realização, só o equacionar dessa hipótese revela com bastante clareza quer a falta de determinação da casa de Bragança na luta pelo trono, quer o intuito em criar junto da Monarquia Hispânica uma situação paralela àquela que construíra com os reis de Avis. Ou seja, entretecer uma rede de parentesco com a família real que a colocasse numa posição de indiscutível preeminência face aos Grandes de Castela. Não reis, mas os primeiros de entre os senhores.

A atenção com que os monarcas castelhanos seguiram os posteriores acertos de casamento dos membros da Casa de Bragança entronca-se no mesmo tipo de preocupações disciplinares. Importava-lhes que estruturassem e reforçassem os laços com a nobreza castelhana e não que criassem alianças com casas reais. Nem com a sua nem com qualquer outra no exterior da Península Ibérica. Pelo menos era essa a plausível lógica que os cronistas da casa, nomeadamente António Caetano de Sousa, emprestaram à política global dos Áustria para com os Bragança, apontando como fundamento os acordos de casamento de D. Serafina (1593), de D. Duarte (1595) e, depois, dos $7^{\circ}$ e $8^{\circ}$ duques de Bragança ${ }^{22}$. E havia, de facto, registos dessa orientação. Um desconfiado conselheiro de Filipe I de Portugal afirmara mesmo em 1580 que «yo fuera de parecer, que V. Magestad com algun justo titulo le hisiera repartir el estado entre sus hijos, y despues casandolos en Castilla, hir à pocos, quitandolos de Portugal, devertindoles el casar en el Reyno, y de la misma suerte fuera de España, siendo esencial el devertile la correspondencia, trato y parentesco de Naciones, y Principes Estrangeiros» ${ }^{23}$.

Neste contexto, compreende-se que a oferta matrimonial que, anos mais tarde, a duquesa D. Catarina recebeu de Filipe I, fosse olhada com desconfiança. Não servia os interesses da Casa e arriscava um dote que cercearia os proventos do ducado, não compensando nisto a honra da união, tanto mais que qualquer possibilidade de descendência estava fora de causa.

No rescaldo da mudança de conjuntura política e das promessas efectuadas, concertaram-se os casamentos de D. Serafina e D. Duarte. Com Grandes da

21 Carta do conde de Portalegre in Idem, ibidem, p. 239. No entanto, a possibilidade de uma união entre os Bragança e a Casa Real hispânica corria entre alguns sectores, levando-os até a interpretar a visita que Filipe II de Espanha fez em 1581 a D. Catarina em Vila Boim como uma manifestação do interesse do próprio monarca em se casar com uma filha da duquesa, BOUZA ÁlVAREZ, Fernando (org., introd. e notas): Cartas para Duas Infantas Meninas. Portugal na Correspôndência de D. Filipe I para as Suas Filhas (1581-1583), Lisboa, Publicações Dom Quixote, 1999, pp. 63-64, nota 15.

22 SousA, António Caetano de: HGCRP, t. IX, 1953, pp. 3 ss.

23 Parecer, sem autor nomeado, de 27 de Agosto de 1580 in HGCRP, t. VI, p. 116. 
Monarquia Hispânica, mas não com príncipes. As propostas de nomes de cônjuges vieram da corte, bem como o significativo lote de mercês que demonstravam a vontade da realeza em agraciar a casa de Bragança, mas também confirmavam a sua condição de vassala da Coroa. É esta a circunstância que justifica que a duquesa D. Catarina tenha contribuído com tão pouco (um quarto do total) para o dote de D. Serafina, garantindo o Prudente a maior parte da verba acordada com D. João Pacheco, marquês de Vilhena e duque de Escalona.

No que se refere ao filho $D$. Duarte, $D$ Catarina também solicitara bem mais do que veio a ser outorgado. E, em 1583 , à data da morte do duque $\mathrm{D}$. João I ainda insistia. Retomava o pedido de um título de duque e uma renda de 10 contos de réis, tudo de juro e sobre terras sitas em Portugal. E enunciava-as. Corresponderiam, no essencial, aos bens do senhor D. Duarte, o seu já falecido irmão. No entanto, a prudente liberalidade de Filipe I de Portugal reorientou geograficamente os futuros estados de D. Duarte para o interior da meseta castelhana, bem longe da raia, e não foi além do marquesado e 4000 ducados $(1,6$ contos) de renda ${ }^{24}$. Também as decisões relativas ao seu casamento foram difíceis. Prolongaram-se por cerca de sete anos e exigiram intervenção de juristas e mediadores na corte. Estava em causa a união com uma herdeira de casa de um Grande - D. Beatriz de Toledo, Monroy e Ayala, filha do conde de Oropesa - e havia que acautelar a sucessão desse património senhorial, bem como dos bens recém outorgados a $\mathrm{D}$. Duarte. A hipotética união destes senhorios com a casa de Bragança era por isso um tema candente, tanto mais que $D$. Duarte pugnava pela sua casa de origem. No final assegurou-se a autonomia do condado de Oropesa, mas aceitou-se a possibilidade de, caso faltassem descendentes directos, os bens próprios de D. Duarte virem a recair na casa de Bragança ${ }^{i s}$.

Os sucessivos e fracassados arranjos matrimoniais de D. Teodósio II ao longo das duas últimas décadas do século XVI foram, em grande parte, fruto do excesso de vantagens que a casa detinha e procurara anteriormente. Surgira a hipótese de o casar com a filha do arquiduque Carlos (duque de Estíria e Carníola), em 1592, que se gorou pelo facto de Filipe I de Portugal pensar casar o príncipe herdeiro nessa mesma casa e não querer que o rei de Espanha ficasse cunhado do Bragança ${ }^{26}$. Ora era esse mesmo conjunto parentesco que D. Catarina buscava e que a motivara nessa escolha a fim «de se ficar por esta via continuando, e acrescentando o parentesco, que os Duques desta Casa sempre tiverão com os Reys deste, e esse Reyno, o que não foi senão por casamentos tais como este» ${ }^{27}$. A inviabilização régia deste consórcio surgiu assim como uma quase afronta à honra brigantina, como, de resto, a própria duquesa nessa carta fez sentir ao monarca. Em 1598, levantou-se a possibilidade do consórcio com

24 BouZA ÁlvareZ, Fernando: «En la corte y en la aldea de D. Duarte de Braganza. Libros y pinturas del Marqués de Frechilla y Malagón», Península. Revista de Estudos Ibéricos, n. ${ }^{\circ}$ 0, 2003, pp. 261-288.-

25 Ibídem, p. 268.

26 Provas, t. VI, p. 194-198.

27 Carta da duquesa D. Catarina a Filipe I, de 11 de Julho de 1595, Provas, t. IV, P. $2^{\text {a }}$, p. 36. 
Maria de Médicis, herdeira do Grão Duque da Toscânia, que acabou por não se concretizar, porque esta veio a casar com Henrique IV, rei de França ${ }^{28}$.

Eram, todas elas, alianças possíveis para casas reais; excessivas para a casa de um vassalo da Coroa. O valido Lerma pressionou a favor da união com $D$. Ana de Velasco, filha do Condestável de Castela e $3^{\circ}$ duque de Frias ${ }^{29}$. Filipe II de Portugal acordou. Pese embora a flagrante discrepância face às anteriores propostas, esta solução foi levada avante. $O$ duque de Bragança contava já 32 anos e era fundamental que tomasse estado e assegurasse a sucessão da Casa. As capitulações matrimoniais tiveram, por isso, lugar em 1602.

Em 1604, o episódio do concerto de casamento de D. Isabel, filha do duque D. Teodósio I, com um Grande do Reino de Portugal - o $6^{\circ}$ marquês de Vila Real e futuro duque de Caminha - está longe de questionar esta política filipina para com a casa de Bragança. A meu ver, só lhe confere mais consistência. Se não, veja-se.

Após a morte do seu único irmão inteiro D. Jaime, D. Isabel ficou como a única filha do segundo casamento de $\mathrm{D}$. Teodósio I e, portanto, como a herdeira forçosa de sua mãe, a duquesa $\mathrm{D}$. Beatriz de Lencastre. No início da centúria de seiscentos esta duquesa velha era ainda viva e habitava com a filha no Alandroal. Disputava há já décadas, mais precisamente desde a morte de seu marido em 1563 , a sua parte na herança de D. Teodósio I, primeiro com o enteado, o duque D. João, e depois com D. Teodósio II. Esta reclamação adivinha-se significativa, tanto mais que os bens iriam no futuro recair por inteiro em $\mathrm{D}$. Isabel. Daqui o cuidado posto pelos Bragança na dilucidação dos bens devidos. Essa atenção, mista de má vontade e preocupação, impusera o prolongamento das demandas e instalara já um profundo mal estar que provocou mesmo o apartamento de moradas entre os duques de Bragança e a duquesa.D. Beatriz de Lencastre e a sua filha $\mathrm{D}$. Isabel ${ }^{30}$.

Assim, este concerto de casamento jogava, na prática, toda a herança devida pelo segundo casamento de $\mathrm{D}$. Teodósio I o que, se tornava $\mathrm{D}$. Isabel numa apetecível herdeira, também significava um duro golpe na fazenda ducal. Tal parece-me justificar bem o silêncio da Coroa relativamente a este consórcio. Por um lado não se lhe pedia qualquer comparticipação, por outro lado consolidava um repartição dos bens brigantinos, que, como se disse já, convinha à suavização dos receios que os Bragança inspiravam.

28 SouSA, António Caetano de: HGCRP, t. VI, p. 204-208.

29 Carta do duque de Bragança ao de Lerma, de Vila Viçosa, 6 de Dezembro de 1601, Biblioteca Nacional de Madrid, ms. 18 634, n. ${ }^{\circ} 38$.

30 Com efeito, procedera $\mathrm{D}$. Beatriz contrariamente às disposições testamentárias de D. Teodósio I que instavam a sua viúva a coabitar em Vila Viçosa com D. João e D. Catarina (Provas, t. IV, P. $1^{a}$, p. 309). Já a questão da heranças tinha por base um desacordo a propósito dos bens do morgado novo instituído pelo duque $\mathrm{D}$. Teodósio I que a duquesa $\mathrm{D}$. Beatriz alegava serem partíveis, contrariando o entendimento dos duques (Idem, ibidem, p.403).

Hispania, LXIV/1, núm. 216 (2004) 39-62 
Diga-se, em breve à parte, que este contrato matrimonial se veio também a revelar polémico. Em 1621 estava instalado o dissídio entre os duques de Caminha por vários motivos, entre os quais o pagamento do dote. A duquesa $\mathrm{D}$. Beatriz alegava ter pago a segunda parcela, ficando assim cumprida a totalidade do valor acordado, no que o genro discordava, não lhe dando por isso a desejada quitação. Parecia mal à Coroa estas quezílias entre gente de tão grande qualidade, pelo que vários foram chamados para moderar as desavenças que se sabiam acesas, entre os quais o conde-bispo de Coimbra e D. Duarte, marquês de Frechilla e sobrinho da duquesa de D. Isabel. Não conseguiram todavia impedir que chegassem ao parecer do Conselho de Portugal e depois ao recurso a juiz privativo ${ }^{31}$. No todo, alegava o duque de Caminha ter em dívida há dezassete anos 40000 cruzados mais os respectivos rendimentos. Não seria verdade, mas o que estava em jogo, como se viu, era, de facto, um dote particularmente elevado (Quadro 5).

Retomando o tópico das lógicas políticas da monarquia face aos Bragança, sublinhe-se que uma vez que este casamento não produziu filhos (como era de resto previsível, dada a idade da noiva), permitiu a livre disposição dos bens dotais. A estreita ligação que $D$. Beatriz sempre demonstrou à sua família de origem foi também aceite por D. Isabel, como se comprova pelas disposições testamentárias de ambas. Assim, a parte das duas na herança brigantina acabou por recair em membros do grupo familiar dos Lencastres, não retornando à casa de Bragança, ao contrário do que era o comum uso entre os seus membros sem descendentes forçosos.

\section{INTERESSES E FRAGILIDADES. O CASAMENTO DO DUQUE D. JOÃO II}

O casamento do duque de Barcelos foi uma preocupação que a casa de Bragança arrastou por mais de seis anos. $O$ esforço diplomático inicial foi orientado para o exterior da Península Ibérica. Na Alemanha e em Itália. Mais concretamente entre as casas de Sabóia, Modena, Pádua, Mântua e Florença.

Vale a pena analisar um pouco mais demoradamente este processo negocial, não apenas para dilucidar os canais de comunicação utilizados, mas também para avaliar o nível de conhecimento que o duque detinha sobre a actualidade política internacional e o lugar que presumia deter nesse concerto de príncipes. Igualmente importante é a possibilidade de aceder - indirectamente é certo - às reacções que as propostas de casamento suscitavam entre as casas italianas.

$\mathrm{O}$ duque $\mathrm{D}$. Teodósio II mantinha uma correspondência assaz regular com o padre Nuno Mascarenhas, membro da Companhia de Jesus e assistente na

31 A correspondência para solucionar este extremado desentendimento no âmago do núcleo familiar dos duques de Caminha ocupou bom tempo a muitos políticos ao longo de todo o ano de 1622. British Library, Egerton, ms. 1136, fls. 32-48v. 
corte de Roma ${ }^{32}$, pelo menos, desde o início da década de $1620^{33}$. Em 29 de Novembro de 1626, surge a menção ao casamento do duque de Barcelos, embora se depreenda que este interesse existia, no mínimo, há já alguns meses. A missiva deixa claro que o duque de Bragança incumbira o jesuíta de prospectar o mercado matrimonial em Itália. Dando-lhe, desde logo, instruções de contactos para avaliar as disponibilidades em diferentes Estados italianos, mas comentando também as informações de que dispunha.

Os primeiros nomes a surgir são os dos Cardeais de Sabóia, Mântua e Florença. No pressuposto que manipulariam as suas conexões familiares, deles se solicitariam as autorizadas informações sobre as senhoras disponíveis, partindo, no entanto, de um primeiro critério de selecção: a existência de laços de parentesco com a casa de Bragança. Dadas as já referidas intersecções matrimoniais dos Bragança com membros da Casa Real portuguesa este crivo definia um universo apesar de tudo bastante considerável. É a ele que o duque se refere elencando os casos possíveis.

Dizia então D. Teodósio II que «este da princesa Maria me parecia mais conueniente alem de outras resons, porque as idades deuem ser mais conforme e nos parentescos abraça tudo». Continuava, afirmando «o de Florença cuido que podera ser mais facil, por se começarem a aparentar com Parma, e assj parece que poderam vir melhor nisso se de parma o não estoruarem, porque cuido que tinham outra pretenção de que não trato, e desta o faço porque o que nos conuem he ficar sempre apparentados com a casa real como sempre forão os desta casa // As de saboja me pareçe que deuem de ter já muita idade, e porventura que as guardara pera seus cunhados que como sam, Reis as podera ir entretendo com isso, ou as não querera casar pera lhe ficarem os dotes em casa, e podia auer mais duuida em ellas parirem, por outra parte o casarem as dittas irmans em Modena, e Mantua ${ }^{34}$, tambem facilita, e mais sendo estas as

32 O Padre Nuno Mascarenhas foi eleito em 1615, por ocasião da congregação geral da ordem, reunida para a eleição do novo geral, Mutio Vitelleschi. Sucedeo neste cargo ao seu irmão, o Padre António Mascarenhas, e manteve-se como assistente de Portugal até à sua morte, em 1637. Cf. ALDEN, Dauril: The Making of an Enterprise. The Society of Jesus in Portugal, Its Empire, and Beyond, 1540-1750, Stanford, Standford University Press, 1996, p. 234, e FrANCO, António: Ano Santo da Companbia de Jesus em Portugal, ed. de Francisco Rodrigues, Porto, Apostolado da Imprensa, 1931, p. 320. Agradeço esta informação a Federico Palomo del Barrio.

33 A colecção das cartas enviadas pelo duque D. Teodósio II ao este membro da Companhia de Jesus em Roma regista o conjunto dos assuntos particulares que o duque pretendia que fossem intermediados por esse eclesiástico tanto junto da Santa Sé, quanto dos titulares de diversos Estados da Península Itálica. Em matéria eclesiástica o principal tema eram pedidos de privilégios relativos às suas comendas da Ordem de Cristo. No que respeita às casas principescas o assunto versava o casamento de seu filho $D$. João, duque de Barcelos. Esta colecção de vinte cartas, com as datas limítrofes de 8 de Janeiro de 1623 e 12 de Maio de 1630, integra o códice 314 do Arquivo Tarouca, depositado na Biblioteca Nacional.

${ }_{34}$ Refere-se a D. Isabel de Sabóia, casada com Afonso de Este, duque de Modena, e a D. Margarida casada com Francisco de Gonzaga, duque de Mântua e Monferrato. A identificação das potenciais cônjuges foi feita essencialmente com recurso a SoUSA, António Caetano de: HGCRP, ts. II e III passim e ao site http://genealogy.euweb.cz, (C) Miroslav Marek.

Hispania, LXIV/1, núm. 216 (2004) 39-62 
derradeiras». E rematava «Se em Mantua há filhas me auise V.R. das partes e nomes dellas, e se tem ou esperam de ter algua cousa». Avisava, porém, o padre que fosse discreto e que falasse «so com pessoas, que não possam ca comunicar, porque quando for tempo, então podemos ca comunicar isto» ${ }^{35}$.

A preferida de D. Teodósio II era pois D. Maria Farnese ${ }^{36}$, filha de Rainúncio I, duque de Parma e neta, portanto, da Princesa D. Maria, irmã da duquesa de Bragança D. Catarina. Era estreito e próximo o parentesco que a unia aos Bragança. Quanto a Florença, indagava pelas filhas do Grão Duque da Toscânia, Cosme II - Ana e Cristina -, sugerindo que a aproximação a Parma que decorria das negociações do casamento da mais velha destas irmãs que dava pelo nome de Margarida, com Eduardo Farnese I, duque de Parma, facilitaria o contacto. As de Sabóia que referia, julgo serem D. Maria e D. Francisca Catarina, filhas da infanta D. Catarina Micaela (e portanto netas de Filipe II de Espanha) e do duque de Sabóia, D. Carlos Manuel. Pelo lado paterno, eram bisnetas da infanta D. Beatriz, filha do rei de Portugal $D$. Manuel, que casara em 1521 com Carlos III duque de Sabóia. Nascidas em 1594 e. 1595, seriam, com efeito, um pouco idosas para o duque de Barcelos (cerca de dez anos mais novo) e justo o receio da possível infertilidade. Já o seu desconhecimento sobre a situação em Mântua explica-se não apenas pelo parentesco mais afastado, mas também porque as duas filhas do duque de Mântua, Vicente Gonzaga estavam já casadas ${ }^{37}$ e a presuntiva herdeira do ducado, neta de Vicente Gonzaga - D. Maria de Gonzaga - estava em negociações com um tio de nome Carlos Gonzaga II, príncipe de Rethel, com quem viria a casar em 1627.

O diálogo sobre o tema reatou-se três anos depois, na epístola de 15 de Julho de 1629. O duque retomou a hipótese mantuana, sobre cuja situação política estava já melhor informado ${ }^{38}$. Por isso inquiria concretamente «se o de niuers, que he agora de mantua tem algua filha». Tinha, com efeito, três, de nomes Ludovica, Benedita e Ana Maria, nascidas em 1611, 1614 e 1616. Eram, pois, candidatas plausíveis. Aventava, de seguida, a possibilidade de Lorena e não desistira também da de Florença. Em Lorena a hipótese pensada deveria ser a princesa Claudia Francisca de Lorena que se encontrava em boa idade (nascera em 1612). Reconhecia, porém, a dificuldade da distância, embora recordasse que na década de 1580 o duque Carlos II de Lorena (avô da princesa Cláudia) se lembrara da casa de Bragança, na pessoa dele D. Teodósio II,

35 Todos os excertos constam da carta de 29 de Novembro de 1626, BN, Arquivo Tarouca, cód. 314.

36 Esta senhora veio a casar em 1630 com Francisco d'Este, duque de Modena.

37 A mais velha, Margarida, nascida em 1590, casara em 1606 com Henrique, duque de Lorena, e veio a falecer em 1632. A mais nova era Leonor de Gonzaga, que nasceu em 1600, e em 1622 matrimoniou-se com o imperador Fernando II.

38 Mântua defrontava, de resto, uma situação complicada, já que entre 1628 e 1630 se defrontavam dois partidos candidatos à sucessão do duque Vicente Gonzaga. Eram eles Carlos de Gonzaga II, que era filho de um outro homónimo e duque de Nevers, que foi protegido por França contra outras linhas sucessórias reivindicadas por Sabóia com o apoio de Castela e do imperador Fernando II. 
para casar a filha Cristina e que tal não fora avante por desleixo, "por ser no tempo das alterações». Congeminava ainda que talvez outros parentes da casa, como o conde de Chalant, pudessem ajudar nessa negociação. Era uma possibilidade, longínqua, todavia. Por outro lado admitia que em Florença estava tudo confuso. Abundavam outras propostas mais atractivas, como a de um irmão do rei de França, e o duque constatava irritado «reçeio que estejão oje tam soberbos como já disse noutra a V.R. posto que não tapauão os ouuidos noutro tempo aos padres que lhe fallauão nesta caza». Finalmente perguntava pelas senhoras de Modena. Seriam estas Catarina e Margarida d'Este de 16 e 10 anos de idade, filhas do duque Afonso III e de Isabel de Sabóia, uma vez que a mais nova - Ana Beatriz - estava fora de causa por rondar apenas os três anos. Mas mesmo Catarina surgia duvidosa, já que «Sobre a mais velha não escreuj a V.R. pollo que me disse da suia idade e dizerem que não era bem sam» ${ }^{39}$.

Um mês e meio depois, em 30 de Agosto, nova carta do duque e nova insistência. Não estava ainda fora de hipótese Margarida d'Este, mas pedia cautela, lembrando que uma senhora dessa família «que morreo nas descalças teue falta de juizo». Dava, todavia, mais ênfase a D. Ana Carafa, neta do duque de Mântua, herdeira de vasto património e duquesa de Stigliano ${ }^{40}$. Dizia que embora tivesse já ouvido tal nome, via um jesuíta italiano, não prestara atenção porque aguardava notícias dos desenvolvimentos dos contactos em curso e porque supusera que esse assunto levantaria mais dificuldades do que agora the parecia ${ }^{41}$.

Nove meses depois o assunto reapareceu. As intermediações iam dando fruto e as negociações pareciam bem encaminhadas. A preferida era a já referida Margarida d'Este, uma vez que até o tio bispo de Sabóia escrevera a D. Teodósio II sobre tal matéria. Adiantava, por isso, «que eu e o duque de Barcellos açeitamos o offereçimento e que se trate logo do dote na forma que puder ser $e$ do modo de sua vinda, por onde e como há de vir e aduirto a V.R. que se fallarem em vir a madrid, que acho nisso muitos inconuenientes porende não poderej vir nisso, // os quais não há em qualquer outro lugar de portugal». A prudência sugeria, no entanto "que Vossa Reverência fosse pairando com a de estilhano de maneira que não perca as esperanças de poder cazar com o duque de Barcellos sem se obrigar a nada» ${ }^{42}$.

39 Estes comentários e citações reportam-se à carta ducal de 15 de Julho de 1629, BN, Arquivo Tarouca, cód. 314.

40 D. Ana Carafa era neta do duque de Mondragone, D. Luigi Carafa-Stadera, Grande de Espanha, Príncipe do Sacro Império, Conde de Fondi e de Carinola, Duque de Traetto cujo domínio territorial se centrava no vice-reinado de Nápoles. Em 1630, quando morreu, foi a neta $D$. Ana quem herdou estes vastos domínios. Viria a casar com o duque de Medina de Las Torres, Filipe Ramiro de Gusmão, que em 1637 foi nomeado Vice-rei de Nápoles. Sublinhe-se que esta é a única referência concreta de hipótese de casamento negociada por D. Teodósio II que os cronistas da casa de Bragança oferecem. Cf. Melo, Francisco Manuel de: Tácito Português. Vida, Morte, Dittos e Feitos de El Rey Dom João IV de Portugal, Pref. e leitura de Raul REgo, Lisboa, Livraria Sá da Costa Editora, 1995, p. 20.

41 Carta de 30 de Agosto de 1629, BN, Arquivo Tarouca, cód. 314.

42 Carta de 12 de Maio de 1630, BN, Arquivo Tarouca, cód. 314. 
Em 18 de Agosto o assunto não estava ainda resolvido. Aparentemente, problemas com os correios impediram que chegasem ao destino as quatro cartas que 0 duque escrevera ao Padre Nuno Mascarenhas «dizendo the que podia açeitar ao cardeal de Saboja o offerecimento da sobrinha filha do duque de modena». Escrevia, por isso, de novo para reiterar o interesse ${ }^{43}$. Perdera-se, no entretanto, um ano. Escassos quatro meses depois, em 29 de Novembro de 1630, morria D. Teodósio II.

Os historiógrafos dos Bragança acordaram e difundiram a ideia de que a mão oculta de Filipe III (ou a de seu valido Olivares) conspirara para inviabilizar todas estas hipóteses. Francisco Manuel de Melo, António de Oliveira Cadornega e António Caetano de Sousa ${ }^{44}$ oferecem-nos, assim, alguns exemplos óbvios: «Pediu o Senhor Duque Dom Teodósio faculdade a el-Rei Dom Filipe pera dar estado a seu filho, o Senhor Duque de Barcelos. Foi-lhe respondido que, como fosse em Portugal ou Castela o poderia fazer. (Evitando com esta reposta o não fizesse e se aliasse com algum Príncipe livre de Itália, com quem tinha apertadas rezões de parentesco» ${ }^{45}$ ou "porque a materia de Estado dos castelhanos era que todas as vodas do Duque de Barcelos se estorvassem, ou que havendo de ser fosse de sorte, que se pudesse diminuir a elevação desta grande casa» ${ }^{46}$.

Parece, com efeito, que o duque $\mathrm{D}$. Teodósio II mandou efectuar todas estas diligências de forma discreta, quando não mesmo sigilosa. A preocupação era evitar que Madrid tomasse conhecimento, podendo daqui inferir-se que tentava evitar interferências negativas que perturbassem a negociação, a fim de posteriormente apresentar o assunto de forma mais ou menos definitiva. É esse o sentido que se retira das instruções iniciais ao Padre Nuno Mascarenhas e também da ordem inscrita na carta de 15 de Maio para que adiantassem todos os preparativos relativos à neta do duque de Modena. - dote, meio de transporte e percursos de viagem.

E, no entanto, e sem que saibamos exactamente as razões, o concerto com a filha do duque de Modena não foi avante. Talvez Filipe III de Portugal, ou alguém por ele, tivesse tido notícias do facto e intervindo. Não se sabe. Todavia, o que sobressai nesta correspondência é o reduzido eco que a casa de Bragança encontrava junto dos príncipes desses Estados italianos. Estes aparentam um razoável desinteresse pela candidatura matrimonial do duque de Barcelos, preocupados que estavam em se aliar a casas principescas politicamente mais significativas e mais próximas geograficamente. Recorde-se que para a maioria destes principados esta foi uma década conturbada, recheada de reivindicações de heranças, e acções militares. Como se disse antes, os casamentos dos descendentes serviam justamen-

43 Carta de 18 de Agosto de 1630, BN, Arquivo Tarouca, cód. 314.

${ }_{44} \mathrm{Na}$ passagem referente ao casamento do duque D. João II (HGCRP, vol. VII, pp. 7-9) António Caetano de Sousa limitou-se a parafrasear, quando não mesmo a copiar, Francisco Manuel de Melo no seu Tácito Português....

4s CaDornega, António de Oliveira: Descrição de Vila Viçosa, introd. de Heitor Gomes TeIXEIRA, Lisboa, IN/CM, 1982, p. 61.

46 SousA, António Caetano de: HGCRP, t. VI, pp. 271. 
te para consolidar acordos diplomáticos e, uma vez que esses recursos eram escassos, havia que ponderar estrategicamente a sua utilização. Neste contexto, a casa de Bragança era absolutamente periférica. Tanto geográfica como politicamente. Não era mais que uma casa senhorial da Monarquia Hispânica, sem qualquer valia para as negociações entre as partes em confronto.

$\mathrm{O}$ duque, embora com azedume, constatava isso. $\mathrm{O}$ trunfo de que se valia era a existência de laços de parentesco forjados em alianças matrimoniais passadas. $\mathrm{O}$ que não reconhecia, porém, era que os casamentos concertados getações atrás se deviam à casa reinante de Avis e não à de Bragança. O parentesco com os Bragança decorria, não de alianças directas, mas do facto de também ter havido Braganças consorciados com ramos segundos da então dinastia reinante de Portugal. E este facto fazia toda a diferença na lógica das alianças internacionais.

Em qualquer caso é interessante sublinhar que neste negócio o duque de Bragança não buscava qualquer aliança específica em Itália. Qualquer possibilidade lhe servia, desde que se garantissem duas ou três condições básicas. A primeira era a que fossem senhoras de casas principescas. Descendentes de ramos colaterais não são sequer faladas, com a excepção da duquesa de Stigliano que era, apesar de tudo, uma rica herdeira. Outras condições eram a idade e estado de saúde. Eram, como é evidente, consideradas fundamentais para assegurar a desejável e necessária sucessão na casa, pelo que encontramos nestas passagens notas à conformidade das idades entre os cônjuges, sobre a facilidade em parirem e chamadas de atenção para com os rumores sobre doenças de que padeciam. Finalmente, vinha a questão do dote. Convém, no entanto, sublinhar, que este tópico não parece constituir a principal preocupação ducal e que as instruções sobre essa matéria eram algo vagas.

Em síntese, parece bem que o duque de Bragança presumia uma reputação que não lhe era reconhecida no panorama internacional. Não se sabe se a casa de Áustria contribuiu directamente ou não para essa marginalidade internacional da casa de Bragança. No entanto, a economia das relações diplomáticas de então torna plausível que essa desvalorização de estatuto decorresse dos próprios cálculos e estratégias dos príncipes italianos.

Fosse como fosse, goradas estas diligências e com D. João já na titularidade do ducado, as sua redes de parentesco em Madrid adiantaram outras propostas. Sem concertação prévia, porém, já que colidiam entre si. Assim, D. Fernando de Faro, $3 .^{\circ}$ senhor do Vimieiro e residente na corte, propunha-lhe para esposa D. Mariana de Toledo e Portugal, filha do $6^{\circ}$ conde de Oropesa, que era, por seu turno, filho único de D. Duarte, marquês de Frechilla e irmão de D. Teodósio II. Alegava, em abono desta opção, que D. João "havia de preferir a eleição de sua varonia» ${ }^{47}$, acrescentando um outro trunfo: essa senhora só tinha um irmão adoentado e frágil, pelo que existiam boas hipóteses de vir a suceder no condado.

47 Melo, Francisco Manuel de: Tácito Português..., p. 30, e SousA, António Caetano de: HGCRP, t. VII, p. 6.

Hispania, LXIV/1, núm. 216 (2004) 39-62 
Já D. Francisco de Melo, futuro $1 .^{\circ}$ conde de Assumar e parente particularmente benquisto do duque D. João, desmerecia essa solução. Estante também ele em Madrid, defendia que se houvesse de casar em Espanha, só o poderia fazer na casa de Medina Sidónia. Citava o exemplo passado do duque D. Jaime e o interesse que o conde-duque de Olivares colocava nesse matrimónio como factores positivos, embora reconhecesse que no que referia as qualidades de nascimento, $D$. Luísa de Gusmão era inferior à descendente dos Oropesa.

A decisão foi tomada com alguma rapidez, uma vez que em 1632 D. Francisco de Melo já recebera poderes para adiantar o negócio do contrato de casamento com o duque D. Manuel Afonso de Gusmão. O interesse do condeduque de Olivares parece ter influenciado de forma determinante este rápido assentimento ducal. Aparentemente D. João preocupava-se em ganhar os bons favores de Madrid e assim procurar activamente maiores vantagens para a sua casa. E, nesse domínio, se a definição do clausulado do contrato matrimonial era importante, as negociações com a monarquia assumiam fulcral relevo.

Os cronistas da casa, ao relatarem este assunto concordaram que as promessas de mercês arrancadas a Filipe III de Portugal foram amplas e se estenderam muito liberalmente à familia ducal. De certa forma, tomaram-nas como as contrapartidas devidas pela aquiescência à união em Castela. $\mathrm{E}$, no entanto, sabemos que não corresponderam à totalidade dos pedidos apresentados pelo duque e que resultaram de um compromisso para o qual o duque também fez cedências. Com efeito, o parecer do Conselho de Portugal sobre o impressivo rol de pretensões era prudente. Alegava que D. João recebia um dote do duque de Medina Sidónia, pelo que a comparticipação da monarquia não tinha que ser elevada. Em todo o caso avançavam com sugestões de contrapropostas que amaciassem as reivindicações brigantinas. Assim uma das mercês reclamadas, porventura uma das que era mais cara à casa de Bragança - a devolução da jurisdição, reguengos e alcaidaria-mor da vila e ducado de Guimarães -, só muito parcialmente foi outorgada. Concedia-se-lhe o título ducal, mas não a jurisdição e as rendas ${ }^{48}$. As demais mercês outorgadas pelo monarca foram então: a renovação das duas vidas que seu pai tinha dos lugares de Rebordãos, Mós, Gustei, Castanheira, Ervedoza, Vale de Prado no termo da cidade de Bragança; que o Conselho de Portugal visse, nas pessoas do Doutor Mendo da Mota e do secretário Diogo Soares, e depois reconhecesse todos os títulos, mercês e privilégios da casa a fim de serem confirmados e renovados até seis meses depois do casamento; que lhe fosse feita mercê de quatro hábitos das ordens militares para os seus criados ou outras quaisquer pessoas que o duque indicasse; que se prorrogasse a mercê relativa aos direitos de importação de canela ${ }^{49}$. O mesmo é dizer que se satisfazia a reputação, sem acrescentamento de rendas e poder político.

48 Copia de Consulta becha a S.M. sobre las pretensiones del Duque de Berganza en Ocasion de casarse con la Señora $D^{a}$ Luisa de Guzman, Biblioteca Pública de Évora, Cod. CVIII/1-7, n 52.

49 BNM, ms. 2363, fl. 115v. 
D. Francisco de Melo que iniciara esta negociação como procurador do duque, foi depois substituído por Francisco Sousa Coutinho que a concluiu. As capitulações matrimoniais foram então firmadas em Madrid em 17 de Novembro de $1632^{50}$. O tratado de casamento foi celebrado em 1 de Janeiro de 1633 e, pouco depois, a duquesa $\mathrm{D}$. Luísa partiu para a sua nova morada. No dia 11 de Janeiro, o duque D. João, acompanhado de um lustroso séquito de gente da sua casa, dirigiu-se à raia para a receber. Aguardou em Elvas, onde, de resto, pernoitou. No dia seguinte, encontrou-se com a comitiva dos Medina Sidónia junto do Caia e seguiram para a Sé de Elvas, onde o Bispo ratificou o casamento. Antes da noite cair, partiram em direcção a Vila Viçosa.

so Capitulações de casamento de D. Luisa de Gusmão, Archivo Historico de Protocolos, Madrid, Protocolo 2053, fls. 263-363v

Hispania, LXIV/1, núm. 216 (2004) 39-62 